\title{
Mitochondria in Health and Disease
}

\author{
Anna Meiliana ${ }^{1,2,}$, Nurrani Mustika Dewi², Andi Wijaya ${ }^{1,2}$ \\ ${ }^{1}$ Postgraduate Program in Clinical Pharmacy, Padjadjaran University, Jl. Eijkman No.38, Bandung, Indonesia \\ ${ }^{2}$ Prodia Clinical Laboratory, Jl. Cisangkuy No.2, Bandung, Indonesia \\ *Corresponding author. E-mail: anna.meiliana@prodia.co.id
}

Received date: March 13, 2019; Revised date: Apr 5, 2019; Accepted date: Apr 8, 2019

\section{Abstract}

$\mathrm{B}$

ACKGROUND: Mitochondrial dysfunction known to be associated with most of human inherited disorders and diseases, including neurodegenerative disorders, cardiomyopathies, metabolic syndrome, muscle weakness, cancer, also obesity.

CONTENT: Mitochondria charges for multiple anabolic and catabolic circuitries, as the main provider for adenosine triphosphate (ATP). Mitochondria also responsible for cellwide stress responses and control non-apoptotic cell death routines, such as autophagy and regulated necrosis. In other words, mitochondria play an extended role in regulating cellular functions, both vital and lethal, from physiological metabolism to stress responses and death to maintain adult tissue homeostasis. Furthermore, mitochondria are crucial

\section{Introduction}

Mitochondria are known as the powerhouses of the cell. They are crucial in producing cellular energy adenosine triphosphate (ATP) production, regulating cellular activities, such as apoptosis, Calcium $\left(\mathrm{Ca}^{2+}\right)$ signaling, redox homeostasis, etc.(1) Since last decade, cell biology researchers found the regulated events of membrane fusion and fission of mitochondria, termed as mitochondrial dynamics, bring forth this organelle as their main interest, together with the mitochondrial network remodeling architecture within the cytoplasm.(2-4) Notably, any abnormality in mitochondrial dynamics could cause for both embryonic and postembryonic development. Therefore, any defect or alteration in mitochondria signaling pathways will lead to a large number of diseases in human, including premature aging, neurodegenerative disorders, muscle weakness, cardiovascular disorders, and cancer.

SUMMARY: Mitochondria perform a dynamic, integrated interconnected network, to maintain tissue homeostasis, beyond the cell boundaries and regulating cells and tissues communication. Certainly any mitochondrial dysfunction could direct to neurodegenerative diseases and metabolic disorders.

KEYWORDS: mitochondria, UPR, mitochondrial quality control, proteostasis, mitohormesis, mitochondrial diseases

Indones Biomed J. 2019; 11(1): 1-15 bioenergetic defects (5), induce embryonic lethality in transgenic animal models (6), also a different group of human diseases (7), confirming the crucial role of this event in physiopathology (8-10). Many studies demonstrated that mitochondria play a role in the essential cellular signaling pathways and mitochondrial dynamics are involved in regulating cellular activity. $(4,11,12)$ Thus, any perturbation in mitochondrial function will affect human pathologies such as type-2 diabetes, cardiovascular, and neurodegenerative diseases.

Mitochondria have their own DNA, named mtDNA, and maternally inherited, not transmitted through nuclear DNA(nDNA). In human, mtDNA is circular, double-stranded circular molecule of $16.5 \mathrm{~kb}$, encoding 13 subunits of the RC 
complexes I, III, IV and V, while complex II is composed of four nucleus-encoded subunit with no contribution from mtDNA. The mtDNA contains 22 tRNAs, and 2 rRNA genes, which form the RNA apparatus serving the in situ translation of the $13 \mathrm{mtDNA}$-encoded respiratory chain subunits. In normal individuals, mtDNAs are all identical to each other (homoplasmy), present in hundreds to thousands of copies in different cell types. Heteroplasmy refer to the pathogenic mtDNA mutations, which is frequently co-exist in variable amount with wild-type mtDNA molecules. The remainder proteome in mitochondria is encoded by nuclear genes, consist of almost 1500 polypeptides translated in the cytosol into proteins, and imported to target the organelles by an active process.(13)

Mitochondrial diseases can present at any age on any organs, affect one in 2,000 individuals. Most mitochondrial diseases occurred due to the genetic mutations that disrupt mitochondrial gene expression (mtDNA replication and transcription, and mitochondria mRNA translation) (1416), affect to mitochondrial oxidative phosphorylation because the assembly of the respiratory chain enzyme complexes and ATP synthase in the mitochondrial inner membrane folds called cristae was failed. This assembling need nutrient-derived reducing equivalents to generate an electrochemical potential across the inner membrane and is essential for organelle functions.(17) This might be explained how a dysfunction in mitochondria could lead to many cell-specific stress responses and will induce a range of human diseases, but the exact mechanism remains poorly understood.(18)

\section{Mitochondrial Biogenesis and Functions}

Mitochondria employ a series of biochemical activities for providing oxidative ATP production in eukaryotic cells. (19) Mitochondria has an inner impermeable membrane, and an outer permeable membrane up to approximately $5 \mathrm{kd}$ molecular mass, to separate it from the cytoplasm. Acetyl-CoA oxidation will derive nicotinamide adenine dinucleotide (NADH) and flavin adenine dinucleotide (FADH) as the electron donors. This electron was needed for electron transport chain of the mitochondrial inner membrane, in order to establish an electrochemical proton gradient across the membrane. When the proton transferred a voltage potential and a $\mathrm{pH}$ gradient is produced, and used by the membrane bound ATP synthase to drive the synthesis of ATP or by uncoupling proteins to generate heat.
(20) The discovery of peroxisome proliferator-activated receptor (PPAR)- $\gamma$ coactivator (PGC)- $1 \alpha$ and family (PGC$1 \beta$ and PGC-1-related coactivator (PRC)) as key players in the regulation of energy metabolism open a major finding of how transcription factors controlling mitochondrial biogenesis by regulating overlapping gene expression programs. $(21,22)$

Mitochondrial biogenesis is an orchestrated process tightly regulated by the activity of both mitochondrial and nuclear factors. Ninety percent of mitochondrial proteins are nuclear-encoded, except the respiratory chain complexes formation which encode by both nucleus and mitochondria. The two genes had to be synchronous for transcription and translating the protein needed for new organelles generation. Any imbalance will lead to proteotoxic stress and subsequent activation of mitochondrial turnover mechanisms.(23-25) After transcription and translation process, nuclear-encoded proteins are folded through some process coupled to the translocase of the outer membrane (TOM)-mediated import (26), then due to their presequence directed to particular mitochondrial subcompartments: the outer mitochondrial membrane (OMM), the intermembrane space (IMS), the gellike structure called inner mitochondrial membrane (IMM), or the matrix (27). These steps are regulated by the AMPactivated protein kinase (AMPK), the mechanistic target of rapamycin (mTOR), and insulin-like signaling (ILS) pathways, together with the signaling cascades triggered by calcium and nitric oxide.(28-32)

The key components for mitochondrial biogenesis are nuclear respiratory factors (NRF)1 and NRF2.(25) NRF1 transcriptional activity is methylation-dependent.(33) NRF2, or also known as GA-binding protein transcription factor (GABP), controls the expression of mitochondrial transcription factors (TFAM, TFB1M, TFB2M) and components of the respiratory chain (COXIV sub- units).(34) In mice, sirtuin (SIRT) 7 deacetylases GABP- $\beta 1$ and trigger its binding to GABP- $\alpha$ thus increasing its transcriptional activity.(35) AMPK as an additional regulator of mitochondrial homeostasis, in response to nutrient depletion, inhibit mTOR to promote mitophagy and activate Unc-51 like autophagy activating kinase 1 (ULK1). Otherwise, in rat hepatocytes, AMPK-mediated phosphorylation of SIRT1 results in the PGC1- $\alpha$ deacetylation and subsequent activation, apparently as adaptive compensation response for enhanced mitochondrial turnover.(36) Aside from energy production as their main role, mitochondria also involved in major cellular processes, including ion homeostasis, lipid metabolism, and initiation of apoptotic cell death. 
Mitochondria as Regulators of

Reactive oxygen species (ROS) and Calcium Signaling

Previously, ROS viewed as a toxic by-product of mitochondrial respiration, and by its name we can advise that it is more chemically reactive than $\mathrm{O}_{2}$, then ROS accused of being cellular damaging agents towards lipids, proteins and DNA. Recent studies suggested its appreciation as a mediator in numbers of cellular signaling pathways (37-40), including growth factor signaling, hypoxic signal transduction, autophagy, immune responses, and stem cell proliferation and differentiation.(41) These propose the perspective of ROS from unwanted product of an imperfect system into a nature specific selection for their signaling, evolving our knowledge about the cellular antioxidant defense system. Many oxidant species gain advantages from ROS specificity of signaling, either in chemical reactivity, stability, and lipid diffusion capabilities. $\mathrm{O}_{2}^{-}$, one of ROS species, is generated when $\mathrm{O}_{2}$ go through one electron reduction by cytosolic nicotinamide adenine dinucleotide phosphate (NADPH) oxidases (NOXs) or $\mathrm{n}$ mitochondrial electron transport chain (ETC) complexes I, II, and III (Figure 1).(42,43) $\mathrm{O}_{2}{ }^{-}$generated by the mitochondrial ETC is released into the matrix and with help of superoxide dismutase 1 (SOD1), cytosolic $\mathrm{O}_{2}^{-}$is rapidly converted to $\mathrm{H}_{2} \mathrm{O}_{2}$.(44) $\mathrm{O}_{2}^{-}$also release complex III into the intermembrane space which can cross over through voltage-dependent anion channels into the cytosol and be converted into $\mathrm{H}_{2} \mathrm{O}_{2}$ by SOD1.(45) Moreover, $\mathrm{H}_{2} \mathrm{O}_{2}$ also produced as a by-product of protein

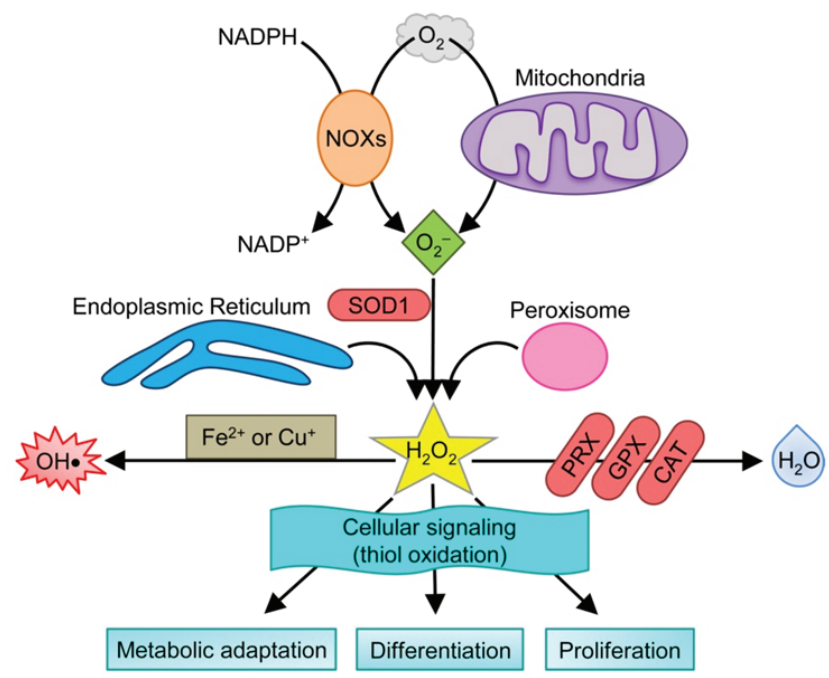

Figure 1. Endogenous sources of ROS signal.(38) (Adapted with permission from Lippincott Williams and Wilkins). oxidation in the endoplasmic reticulum (ER), as the end product in many peroxisomal oxidation pathways such as in the $\beta$-oxidation of very long-chain fatty acids, and by a wide range of enzymes including cytochrome P450. (46) Important thing to note is that ROS specific target at proximal location to these oxidant-generating systems. By this paradigm shifting towards ROS, we need to elucidate the molecular mechanism of ROS signaling in facilitating oxidation, and the possibilities of its potential for providing new therapeutic avenues for a myriad of diseases linked with excessive ROS.(37)

$\mathrm{Ca}^{2+}$ signaling has become the star for coordinating various extracellular stimuli and triggers the cellular function during the past century. $(47,48)$ Recently mitochondrial $\mathrm{Ca}^{2+}$ uptake take over the stage as the controller for intracellular $\mathrm{Ca}^{2+}$ signaling, cell metabolism, cell survival and other cell-type specific functions as it effectively buffering cytosolic $\mathrm{Ca}^{2+}$ levels and regulating the effectors. Mitochondrial $\mathrm{Ca}^{2+}$ transporters reveals recently, draw the attention for investigation and molecular intervention.(49) Accumulation of $\mathrm{Ca}^{2+}$ in mitochondria regulates the organelle metabolism, including its main task to produce ATP by oxidative phosphorylation. Three matrix dehydrogenases of mitochondria were activated by low concentration of $\mathrm{Ca}^{2+}$ : pyruvate dehydrogenase is regulated by a $\mathrm{Ca}^{2+}$-dependent phosphatase, and $\alpha$-ketoglutarate- and isocitrate-dehydrogenases are regulated by direct binding of $\mathrm{Ca}^{2+}$ to these enzymes.(50-52) When $\mathrm{Ca}^{2+}$-sensitive dehydrogenases stimulated, NADH availability increased and the electrons flow down the respiratory chain, proposed increased ATP synthesis adjust to the cells need.(53) Some genetic disorders affect mitochondrial function due to the defect in respiratory chain thus reduce the driving force for $\mathrm{Ca}^{2+}$ transfer, therefore the ATP production also reduced. $(54,55)$

$\mathrm{Ca}^{2+}$ accumulated in mitochondrial matrix through IMM across the steep electrochemical gradient via an electrogenic pathway with help of $\mathrm{Ca}^{2+}$ uniporter (MCU). MCU has a $\mathrm{V}_{\max }$ of $>1400 \mathrm{nmol} \mathrm{Ca}^{2+}$ per $\mathrm{mg}$ of protein per min and can be inhibited by Ruthenium redl and lanthanides.(56-58) $\mathrm{Na}^{+} / \mathrm{Ca}^{2+}$ exchangers (mNCX) and mitochondrial $\mathrm{H}^{+} / \mathrm{Ca}^{2+}$ exchangers (mHCX) counteract the MCU-Ca ${ }^{2+}$ accumulation, and insensitive to ruthenium red but can be inhibited by benzothiazepine analogues, such as diltiazem, clonazepam and CGP-37157.(59-61)

Besides its property as $\mathrm{Ca}^{2+}$-binding proteins, mitochondria in other side may act as fixed buffer of $\mathrm{Ca}^{2+}$ large elevation from a subcellular domain. This will influence cellular $\mathrm{Ca}^{2+}$ signals, and hence cell function. 
(49) Mitochondrial $\mathrm{Ca}^{2+}$ performs two manner during physiological variations of workload (Figure 2). Uptake via the mitochondrial $\mathrm{Ca}^{2+}$ uniporter is required to meet the energy supply demand, while keeping the antioxidative capacity in a reduces state so ROS emission won't be disproportionate.(62) The architecture of mitochondrial calcium uniporter is shown in Figure 3.

\section{Quality Control of Mitochondrial Proteostasis}

In a cell, mitochondria best known as essential organelles, and the powerhouse in generating large amount of energy from food into ATP by an electrochemical proton gradient across the inner membrane activate the ATP synthases. Mitochondria manage the central functions for amino acids and lipids metabolism, as well as iron-sulfur clusters and heme biosynthesis.(66-69) Mitoproteases is a highly regulated proteolytic reactions performed in mitochondria, including protein synthesis, quality control, mitochondrial biogenesis and dynamics, mitophagy and apoptosis. Any impaired or dysregulation function of this degradative function of mitochondria is associated with aging-related diseases such as neurodegenerative disorders, metabolic syndromes and cancer.(70)

Current proteomics and bioinformatics approaches make it possible to define a comprehensive inventory of mitochondrial proteins that role in maintaining mitochondrial healthy function. $(71,72)$ Encoding by two different genomes, mammalian mitochondria harbor their own genome, encoding for 13 polypeptides aside from those synthesized by nuclear genes. The mitochondrial-encoded proteins compose the core components of the respiratory chain complexes, assemble with imported of nuclearencoded proteins to achieve efficient respiratory chain complex of mitochondria. Discoordination of this process may result in unpartnered proteins, which are prone to misfolding or aggregation. ROS, as an inevitable byproduct of the generation of ATP through oxidative phosphorylation, also become another challenge imposed upon mitochondria. When reacting with proteins, DNA or lipids, ROS could result in accumulation of oxidatively damaged products, making them more prone to oxidative damage, and lead to depolarization of the mitochondrial inner membrane. This could propose the outer membrane permeabilization,

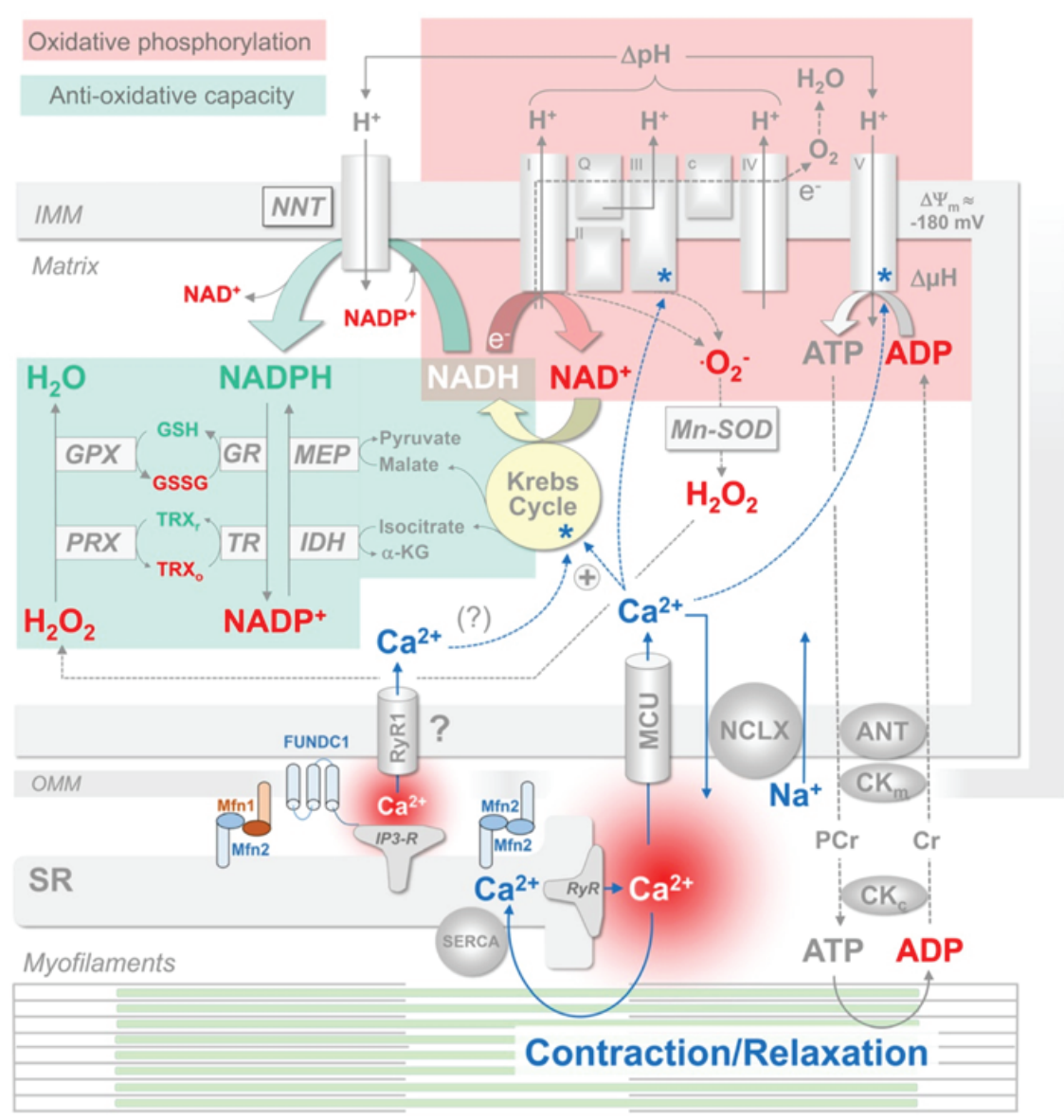

Figure 2. Role of mitochondrial $\mathrm{Ca}^{2+}$ uptake for ATP production and ROS elimination.(62) (Adapted with permission from American Heart Association). 


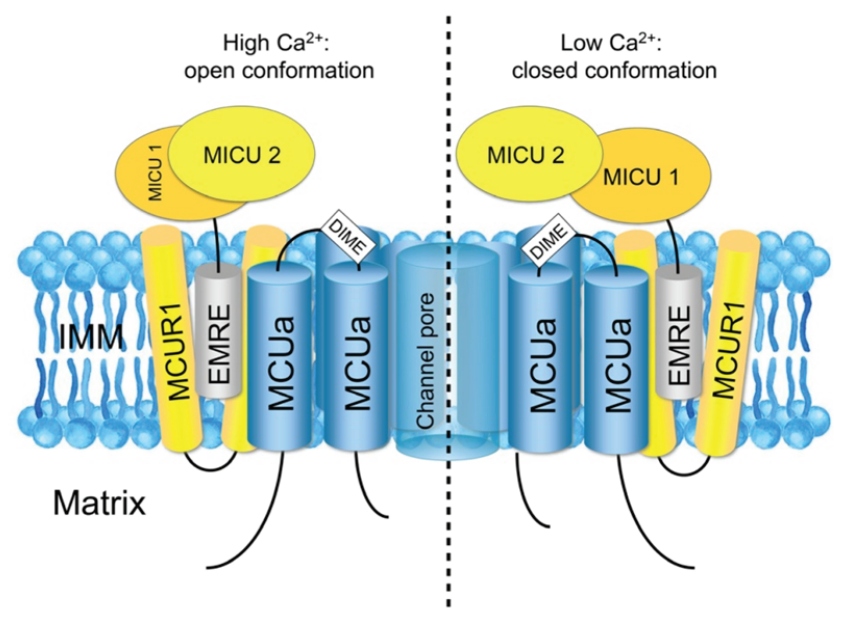

Figure 3. Mitochondrial calcium uniporter architecture and regulation.(62) (Adapted with permission from American Heart Association).

make it possible for pro-apoptotic proteins to release from intermembrane space into the cytosol, and initiating the apoptotic cascade. $(73,74)$ Mitochondria has developed its own mechanism for quality control involving damaged protein or organelles removal to keep the homeostasis of its functional network.(75-79) Blunted quality control will affect in defense pathways for cellular homeostasis and survival and of course the overall cell health, correlated to aging, prevalent neurological disorders like Parkinson's disease and spinocerebellar ataxia.(80) Mitoproteases together with the cytosolic ubiquitin-proteasome system (UPS) form the first line of cellular defense by facilitating the removal of damaged, oxidized or misfolded mitochondrial proteins.(81) Figure 4 explain the mechanisms of mitochondrial quality control briefly.
The first line of mitochondria, from bacteria to higher eukaryotes defense mechanism action in the molecular level, involves the conservation of intraorganellar protein quality control machinery, including chaperon and various proteolytic enzymes. UPS and a mitochondriaspecific unfolded protein response (UPR) also influence mitochondrial protein quality control, by constricting the increasing of misfolded proteins in the organelle. $(82,83)$ The second line for quality control emerge due to the dynamic nature of mitochondria itself. The organelles naturally tend to constantly fusing and dividing mediated by dynaminlike GTPases in the OMM and IMS. $(84,85)$ By fusion, a damaged mitochondrion, means it's defect in certain components, will fuse with a healthy neighbor and replenish its stores.(75) The third stage of these quality controls gate occurs on a cellular level, where the mitochondrial damage were more extensive that the entire cell need to be totally turnover through apoptosis. $(86,87)$

On contrary, mitochondria fissions aim to increase the organelles numbers within the cells prior biogenesis, and separate the defect organelles for autophagic degradation $(88,89)$, and then by fusion these components will be mix and distribute evenly. Thus, by fusion and fission mitochondrial biogenesis, distribution of mtDNA, and proteome could be facilitated. Practically, chaperones and proteases protect mitochondria protein-folding environment from inevitable errors in expression and assembly as well as prevent the prevent accumulation of unfolded and orphaned subunits.(76) Recent comprehensive knowledge in mitochondrial genetics improve the diagnosis to prevent severe mitochondrial disease, and had a major impact on patient care as well as rise new challenges for therapies in mitochondrial disorders.

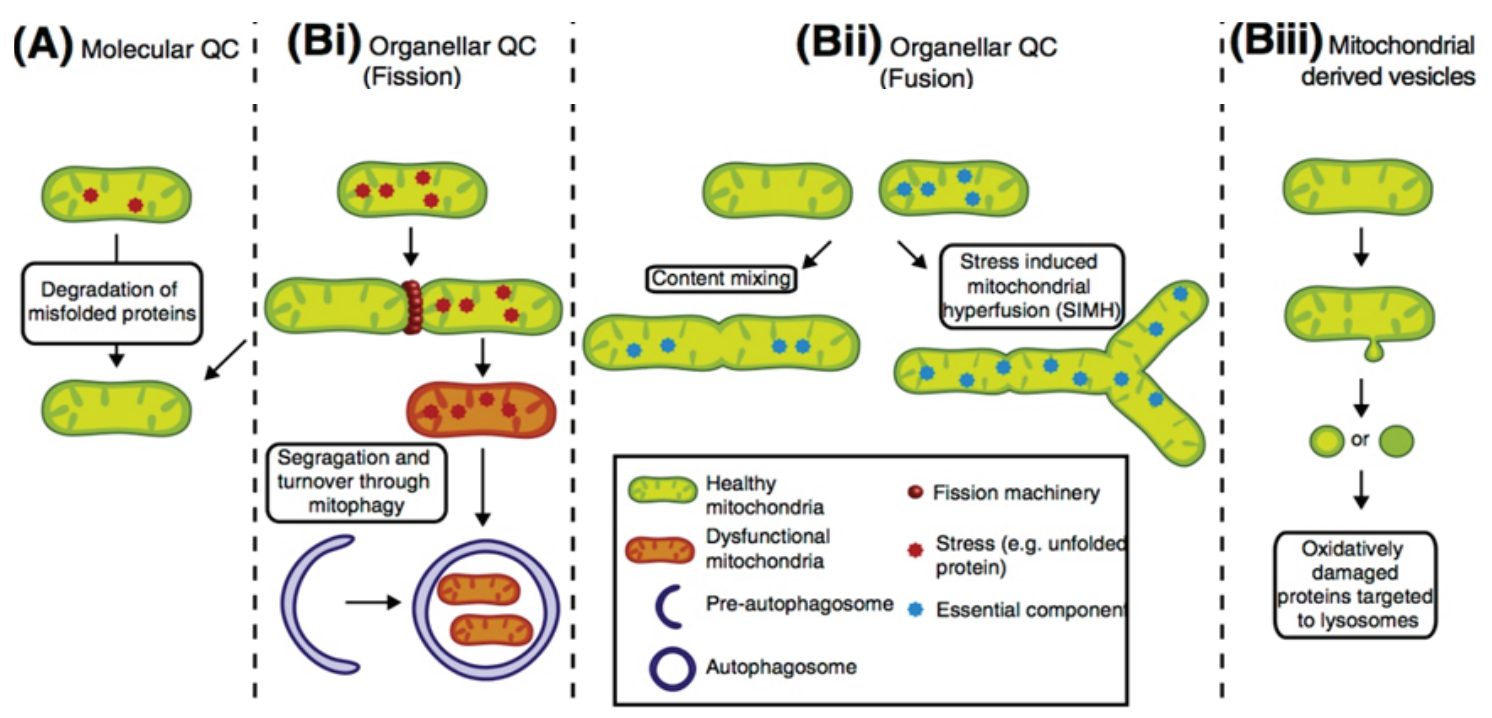

Figure 4. Mechanisms of mitochondrial quality control.(81) (Adapted with permission from Elsevier). 


\section{Mitochondrial and Nucleus Communication}

Mitochondria import more than 1,000 different proteins from the cytosol to perform the bioenergetics, metabolism, and apoptosis function. The protein import machinery was assumed to be constitutively active and not depend on any exact regulation. After all, recent studies found a multiple levels of mitochondrial protein import regulation which were connected to cellular metabolism, signaling, stress, and pathogenesis of diseases. Mitochondrial fitness can be monitored by this activity and also represent the biogenesis regulation, composition, and turnover of the organelle.(69) Nucleus-encoded mitochondrial precursor proteins possess targeting signals which are recognized by receptors on the mitochondrial surface, and direct the precursors to their functional destination in the mitochondrial sub-compartments. These targeting signals can be distinguished into two main groups. $(63,64)$ The first group is the amino-terminal extensions of precursors. This is the classical mitochondrion-targeting signals. Their presequences removed after import into mitochondria by a proteolysis. The second one are some precursor proteins with no particularly cleavable extensions but contain internal targeting signals that remain part of the mature protein including different types of precursor proteins and targeting signals (Figure 5).(67)

Many researches focus on excavating these structural analyses of mitochondrial import components, besides of single-particle electron microscopic analysis of purified translocase complexes (90-93), receptor domains, mitochondrial chaperones and the processing peptidase MPP (94-100). High resolution structures of the membraneintegrated translocation channels, were also important to dig the molecular mechanisms of membrane translocation including that of preproteins in transit.

Mitochondrial function was controlled by nuclear transcription, including the organelle function and capacity coordination, in response to intrinsic and extrinsic signals either alterations to the cell's redox state, nutrient deprivation, and (in muscle) exercise.(101-103) These will increase in mitochondria biogenesis, boost the mitochondrial mass and bioenergetic capacity. An array of transcription factors (TFs) together with co-activators activate and coordinate nuclear and mitochondrial genes expression.(104,105) NRF-1 and NRF-2 are the principal TFs for biogenesis, by controlling the expression of key mitochondrial components involved in oxidative phosphorylation (OXPHOS), haem biosynthesis, the function and regulation of mtDNA, and antioxidant defences.(106) The oestrogen related receptor (ERR)- $\alpha$, the cAMP response element (CREB), and the Ying Yang 1 (YY1) transcription factor also role as $\mathrm{TF}$ in the regulation of mitochondrial genes. Other TFs such as ERR- $\alpha$ regulates oxidative metabolism through its control of $\beta$-oxidation related genes (106), and CREB and YY-1 are involved in the expression of ETC. protein components.(107,108) All of them with transcriptional co-activators in the nucleus integrates into the program of biogenesis.(109)

Retrograde (RTG) signaling occurred as a respond to altered mitochondrial bioenergetic state, the expression of

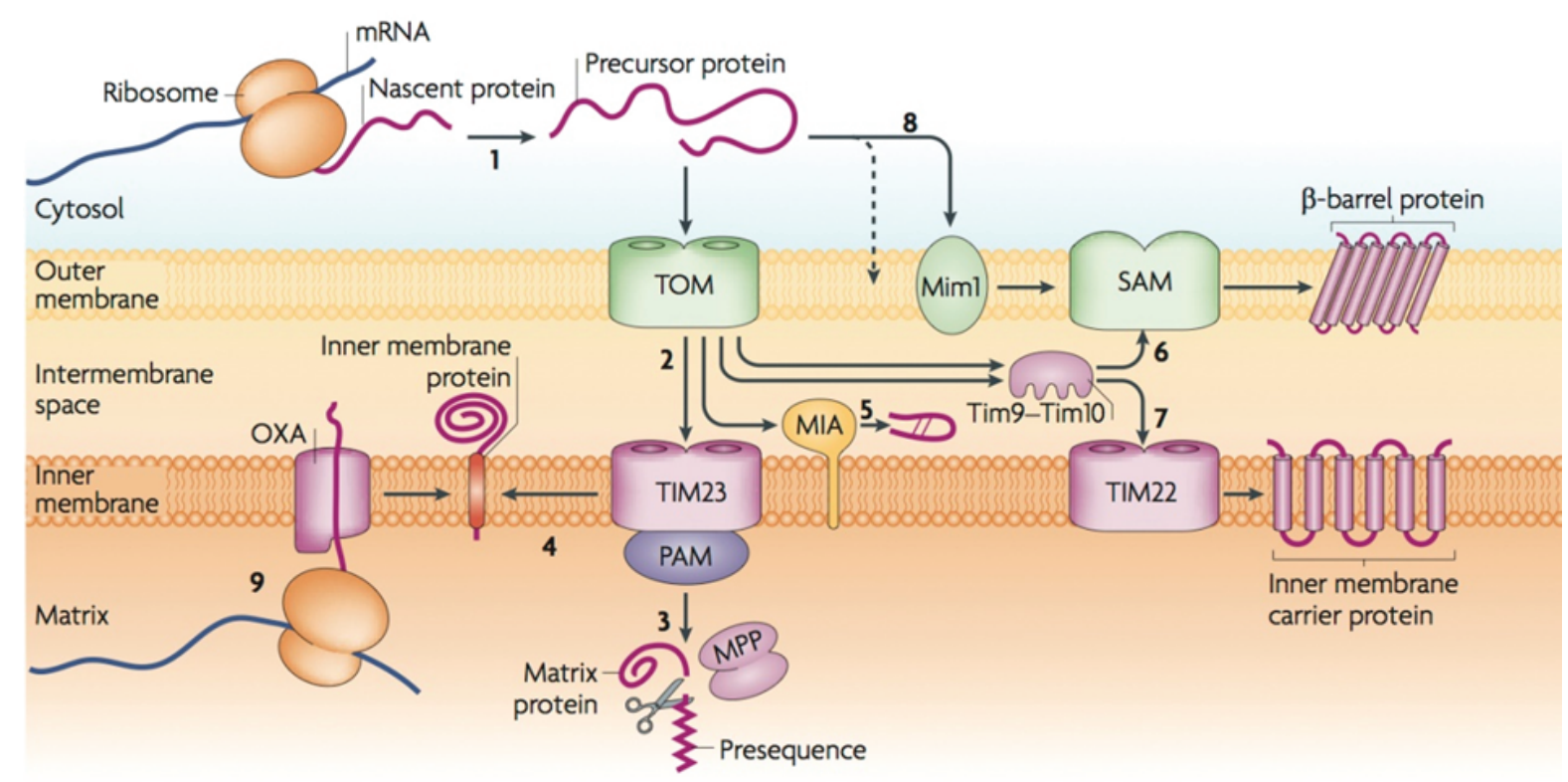

Figure 5. Biogenesis pathways of mitochondrial proteins.(67) (Adapted with permission from Springer Nature). 
nuclear encoded genes will be increased, and compensating the effects of mitochondrial dysfunction or stress. Rather than being a part of mitochondrial quality control systems, RTG system are the stress response pathways complementary to mitochondrial quality control, which activate counter mechanisms to bioenergetic deficiencies caused by mitochondrial dysfunction. There were not enough studies in mammalian cells about this, but some researches in yeast have provided interesting observations that perturbations to mitochondria such as the loss of mtDNA (i.e., petite or rho0 cells) lead to the activation of TF by RTG1, RTG2, and RTG3 (RTG1-3) proteins. RTG signaling in yeast induce the activation of the glyoxylate cycle and the upregulation of fatty acid $\beta$-oxidation thus proposed the alter in the metabolic function, involving abundant variety of carbon sources, such as acetate, and compensating for a reduction in capacity or lack of OXPHOS.(110) Involvement of TOR signaling in the RTG signaling pathway open a possibility of such system in higher eukaryotes, since TOR signaling also found from yeast to humans although its sphere of activity may be slightly changed between species.(111)

Mitochondrial genome can communicate and function synergistically with nuclear expression regulate by specific sequence alterations that categorize mtDNA in haplogroups as mtDNA haplotypes, besides being useful to trace maternal phylogenetic lineages.(112) mtDNA variations are specifically associated with disease phenotypes related to specific sequence alterations in mitochondrial components, and can be measured through the bioenergetic and other mitochondria functional aspects, such as a decrease in respiratory function.(113) There are large groups of human mtDNA pathogenic mutations known to be correlated with clinical phenotypes (114), such as the A3243G mutation in the gene encoding mitochondrial tRNALeu (115), is known to be associated with mitochondrial encephalomyopathy, lactic acidosis, and stroke-like episodes (MELAS), and also promote the development of some other clinical phenotypes. (109) We could conclude that mismatch between the two genomes, the nuclear and mitochondrial affect in mitochondria quality and cellular health. $(109,116)$

\section{Mitophagy}

One of the cellular components catabolism process including cytosol, organelles and protein aggregates, is autophagy, over their encapsulation by a double-membrane structure known as the autophagosome.(117,118) Autophagy will recycles intracellular components to compensate for nutrient deprivation and also selectively eliminates organelles in order to maintain their number and quality control.(89)

Autophagy selectively eliminate mitochondria, in conjunction with mitochondrial biogenesis, to maintain the steady-state mitochondrial number that are needed to meet metabolic demand. Mitophagy through some distinct steps selectively removed any defective or superfluous mitochondria and target them to autophagosomes to maintain quality control (Figure 6).(89) 'Mitochondrial quality control' involving the coordination of mitochondrial dynamics, mitophagy, and biogenesis to keep up a healthy pool of mitochondria. Mitochondrial dynamics refer to its constantly modified morphology by fission and fusion events, all while they are being shuttled throughout the cell. This way, fission and fusion allow damaged mitochondria to complement each other. PTEN-induced kinase 1 (PINK1)/ parkin pathway affecting fission and fusion, but it is not known how this could cause dopamine neuron degeneration. Under stressful conditions, such as nutritional deprivation, two damaged mitochondria with mutations in different genes can fusion and allow functional complementation by RNA and protein components diffusion result in a newlyformed mitochondria and rescuing its function.(119) The lack of mitochondrial function rescuing ability will render cells to become more vulnerable to mitochondrial deficits. In reverse, by fission mitochondria break into smaller pieces to facilitate transport and autophagic degradation of damaged mitochondria. Surprisingly, fission often leads to dissociation the damaged components from resulting mitochondria, resulting in one highly functional mitochondrion and another damaged mitochondrion with reduced membrane potential.(120) So, impaired fission could risk to the ability of mitophagy in recognizing the dysfunctional mitochondria and even to transport them to and from neurites, which is essential in long and energetically demanding cells, such as neurons.(121)

Therefore, mitochondria quality controls include fission and fusion, mitophagy, transport, and biogenesis. Recent studies on Parkinson's disease (PD), a progressive neurodegenerative disease that causes a debilitating movement disorder, implicated $\mathrm{s}$ defect in parkin and PINK1 related to each axis of mitochondrial quality control. Mutation in autosomal recessive PD at two genes encode OMM kinase PINK1 (122) and the cytosolic E3 ubiquitin ligase parkin (123), two proteins involved in suppressing mitochondrial damage in flies (124-126). Impaired in these will lead to loss of flight muscle and dopaminergic neurons, also affecting to male sterility that is ameliorated by promotion of mitochondrial fission.(127-129) 


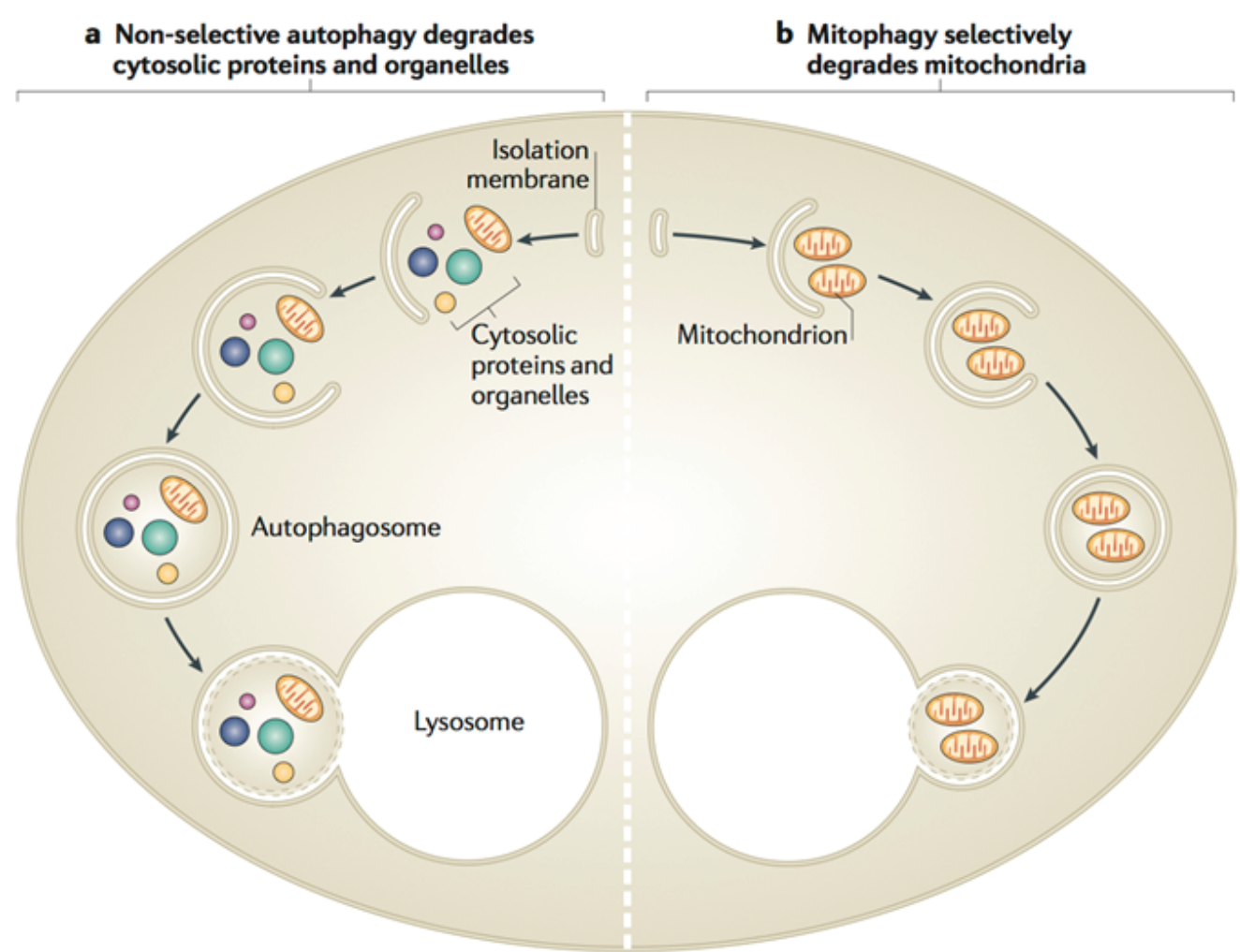

Figure 6. Non-selective autophagy and mitophagy have different roles.(89) (Adapted with permission from Springer Nature).

In autosomal recessive $\mathrm{PD}$, parkin gene mutation is the most common cause. The gene encodes a 465 -amino acid E3 ubiquitin ligase capable of mediating mono- or polyubiquitination using different ubiquitin linkages via lysine 27, 29, 48, and 63 of ubiquitin. Investigation from mouse model and postmortem PD brain samples showed that parkin is inactivated by post-translational modifications, including oxidation, nitrosylation, addition of dopamine, and phosphorylation by c-Abl, which is important for stressactivated nonreceptor tyrosine kinase and is activated in sporadic PD brains and in animal models of PD.(121)

Autophagy and apoptosis manage the turnover of organelles and proteins within cells, and of cells within organisms, respectively. Many stress pathways sequentially bring up autophagy and apoptosis within the same cell. Commonly, autophagy and apoptosis blocking and shuts off each other, for exceptional in some special cases autophagy or autophagy-relevant proteins will induce apoptosis or necrosis, where autophagy degrade the cytoplasm excessively, leading to 'autophagic cell death'. Communication between autophagy and cell death pathways influences the normal clearance of dying cells, as well as immune recognition of dead cell antigens. Thus, the relationship between autophagy and apoptosis has an essential affect in pathophysiological consequences. $(130,131)$

\section{Mitochondrial UPR and Mitohormesis}

Mitochondrial function affects a lot of essential cellular and organismal function, therefore many cell's mechanisms or pathways have evolved to monitor mitochondrial function and provide a fast respond against mitochondrial stress to recover organelle activity, referred as the RTG responses. This pathways upstreaming the initial signals of mitochondria to communicate with cytosol and nucleus and impact gene transcription and protein synthesis in a protective manner.(132) One potential mechanism to asses mitochondrial quality involving the organelle metabolites such as ATP or iron-sulfur clusters (133) and monitoring mitochondrial protein import efficiency (134). In order to function properly, over than 1,000 proteins composing mitochondria, of which $\sim 99 \%$ are encoded by nuclear genes and translated on cytosolic ribosomes, then later imported into mitochondria, where they are appropriately folded and assembled. Transit across the mitochondrial inner membrane requires the Tim 23 complex and a completed tricarboxylic acid cycle (TCA) cycle and OXPHOS system to keep the membrane potential and the mitochondrial chaperones located within the matrix. $(65,135,136)$ Therefore, the mitochondrial function could be described by the protein import efficiency. 
Proteostasis can be briefly determined as protein homeostasis, means all the cellular pathways that govern the production, folding and degradation of proteins, necessary for cellular and organismal functionality and survival. The UPR is a complex pathways of cellular stress response to ensure proteostasis in different subcellular compartments, with finely communicated with the nucleus, have evolved in the cytosol, endoplasmic reticulum and mitochondria. Proteostasis dysfunction was correlated to several age-related diseases due to protein aggregation. (137) Mitochondrial unfolded protein response (UPRmt), just recently discovered, not like endoplasmic reticulum (UPRER) and the cytosolic heat shock response (HSR) that have been first extensively studied $(138,139)$, also role in on the complex relationships between mitochondria and the nucleus $(82,140)$.

Proteostasis in the mitochondria is provided by an elaborate PQC network, composed of two main functional groups of proteins, chaperones and proteases $(76,79)$. Chaperones mtHsp70, Hsp60 and Hsp10 fold and assemble proteins that are imported into the mitochondria and refold damaged mitochondrial proteins. Each mitochondrial compartment has specific ATP-dependent protein quality control (PQC) proteases to digest any excess proteins that are unassisted by chaperones: the ClpXP and Lon proteases in the matrix, the i-AAA (Yme1L1) and m-AAA proteases (Afg312 and Spg7), acting in the IMS and matrix, respectively. These PQC chaperones and proteases are induced upon mitochondrial proteotoxic stress as a result of a RTG mitochondria-to-nucleus signaling termed UPRmt, or can be described as a transcriptional response due to mitochondrial dysfunction or the accumulation of unfolded proteins within mitochondria in the cell.

Studies performed to revealed the pathways using mitochondrial chaperones and proteases as UPRmt biomarkers, found many conditions to trigger UPRmt, most of which interfere with the mitochondrial proteostasis, including disturbing the PQC system or by increasing the load of damaged, unfolded or unassembled proteins, with the intention to alleviate proteostatic stress in mitochondria and promote cell survival along with the repair and recovery of defective mitochondria.(141,142) Thus UPRmt maintain the stability of mitochondrial function, metabolic adaptations, as well as an innate immunity.(143) While impaired protein quality control and accumulation of misfolded and unfolded proteins direct to proteostasis impairment role in age-related decline, increasing the expression of chaperone, limiting translation, or increasing protein turnover otherwise has been implicated in shifting mitochondrial dysfunction into lifespan extension by hermetic mechanism.(142)

UPRmt is induced by manipulating ETC via downregulation or inhibition of single (or groups of) ETC components, either by encoded mtDNA or nDNA (144), resulting a mismatch between mtDNA and nDNA encoded ETC subunits and an orphaned unassembled subunits conceived. This subunit need to stay associated with chaperones, termed as mitonuclear protein imbalance.(144) ETC subunits also downregulated by cco-1 (complex IV) RNA interference $(145,146)$, in isp-1 (complex III) or clk1 (ubiquinone synthesis) mutant strains $(146,147)$, or by using pharmacological ETC inhibitors, such as antimycin $(148,149)$ and rotenone (148). Therefore, mitochondrial biogenesis activation by resveratrol or rapamycin (144), or $\mathrm{NAD}^{+}$levels boosting by the $\mathrm{NAD}^{+}$precursor, nicotinamide riboside (NR), or by inhibiting $\mathrm{NAD}^{+}$consumption, as seen after treatment with PARP inhibitors (150), trigger UPRmt by similar mechanisms. However, in $\mathrm{NAD}^{+}$level raising, mitonuclear imbalance created due to specifically increasing of transcription and translation of mtDNA-encoded ETC subunits, thus triggers the UPRmt.(151)

Under stress, mitochondria will activate several lines of defense. Started with temporarily blocking the production and import of new mitochondrial proteins. General control nonderepressible (GCN)-2, a specific kinase in worm (152), and protein kinase R (PKR) in mammals (147), phosphorylate eIF2a and leads to global translation attenuation. Yme111 protease in mammals, selectively degrades the translocation pore component Tim17A and specifically reduce the mitochondrial import and functions, consistent with the reallocation of ATP production to glycolysis in the cytoplasm. $(153,154)$ In stress condition, both mitochondrial dynamics and mitophagy pathways contribute to reconstitution of cellular homeostasis, by redistribution and eliminate of the irreversibly damaged elements of mitochondrial network. Under strong mitochondrial stress, insufficient levels of mitophagy and UPRmt activation will induce apoptosis and has negative systemic effects on whole organism physiology. $(76,79)$

Many publications so far have provided useful information about the communication between mitochondria and nucleus, also how its roles including UPRmt pathways in lifespan regulation from simple model organisms tomammals. However, UPRmt is a transcriptional response that affects over 400 genes controlling different aspects of cell physiology, so we are facing a scientific challenge for years to come to find 
which one is the most important and the most available to be manipulated in ameliorating the defects associated with mitochondrial dysfunction. $(140,143)$

In mild stress, mitochondrial rapidly activate a coordinated response in cytosolic signaling pathways that ultimately alter nuclear gene expression, named mitohormesis, and leave the cell less susceptible to subsequent perturbations. A comprehensive understanding of mitohormesis will provide a better insight into our susceptibility for disease and potentially provide a unifying hypothesis for why we age.(155) Hormesis in general can be defined as any cell response that exhibits a biphasic response to exposure to increasing amounts of a substance or condition.(156) Here, we focus on one form of hormesis, termed mitohormesis, briefly defined as a respond to mild mitochondrial stress due to any insults, exhibit a broad and diverse cytosolic and nuclear response. This response could be varied but appears to induce a wide-ranging cytoprotective state generating in long-lasting metabolic and biochemical changes and finally may reduce our susceptibility for disease and expand out lifespan.(155,156) Then we may warp up that mitochondrial stress induce mitohormetic response which provided both short term metabolic benefits and the potential for long term benefits in increased stress resistance and longevity.

\section{Mitochondrial Diseases}

Human mitochondrial disorders are long-term, genetic, often inherited disorders, in consequence of mutations in mitochondrial and/or nuclear DNA that lead to mitochondria fail to produce enough energy for the body to function properly.(15) Currently, mitochondrial diseases are still incurable, so available treatments only help to relieve the symptoms. The diseases can manifest at any age, at any organ or organ system, including in multiple organs that may have no apparent functional links to each other, such as the brain and liver, or pancreatic $\beta$-cells and the auditory system, and can be inherited, either from an autosome, the $\mathrm{X}$ chromosome, or maternally depending on where the gene defect lies. Children may recover from one phenotype and later develop another ones. $(17,18,157)$ We don't have a comprehensive understanding about the natural history of mitochondrial disease until recently, but longitudinal cohort studies involving a large population indicating clinical progression in mitochondrial disorders caused by both mtDNA and nuclear gene mutations.(158)
Genes identification for mitochondrial disorders lead to better mechanisms understanding, such as mutations affecting the structural subunits of the mitochondrial respiratory chain (159) was accompanied by the molecular dissection of the assembly apparatus for complexes IV (160), then I, III (161) and finally V (162). Further observation also showed dual functions and multiple functions in several assembly protein or the structural peptide components of complex I.(163) The most interesting finding is that most sophisticated disease mechanisms turn out not to connected directly to oxidative phosphorylation and ATP synthesis, and in adult, the single most important group heading to disorders affecting the maintenance of mtDNA.(164)

Majority abnormalities in mtDNA expression associated with mtDNA depletion due to insufficient and/ or unbalanced deoxyribonucleoside triphosphate (dNTP) pools, impact in aberrant mtDNA maintenance and translation then lead to protein stress (resulting from defects in translation or unbalanced translation of respiratory chain components that are encoded by mitochondrial and nuclear genomes), replication and transcription stress as well as stress.(165) A number of credible evidence pointed that mitochondrial disorders mainly triggered by mitochondrial stress responses because of a primary molecular defect in the organelle, and not the defects in oxidative phosphorylation per se.(18)

Mitochondrial stress responses activate the quality control pathways then initiate reverting signals in mitochondria to activate the nuclear genetic programs for organelle maintenance and heighten the quality control. Studies in human, mice and cell lines showed a robust nuclear transcriptional stress response has also ben induced in coping with the defect on mtDNA maintenance and translation (165-169), upregulating the genes that carry a conserved amino acid response element (AARE) in their upstream regulatory region (170). The amino acid response element (AARE) functions as the binding site of activating transcription factors (ATFs), and was found in different isoforms for ER UPR and mtUPR.(171) These, explained the complex molecular mechanisms responsible for defects of oxidative phosphorylation. A large cohort study recently, after last 25 years of intensive studies aimed to explore the genetic causes and the pathogenic mechanisms of mitochondrial diseases, involving more than 3,000 subjects, phenotypic subgroups and the relationship to genotype, driven the "proof of concept" successes and providing rich natural history data sets to be translated and tested on patients. A proof of maturity in mitochondrial medicine, and 


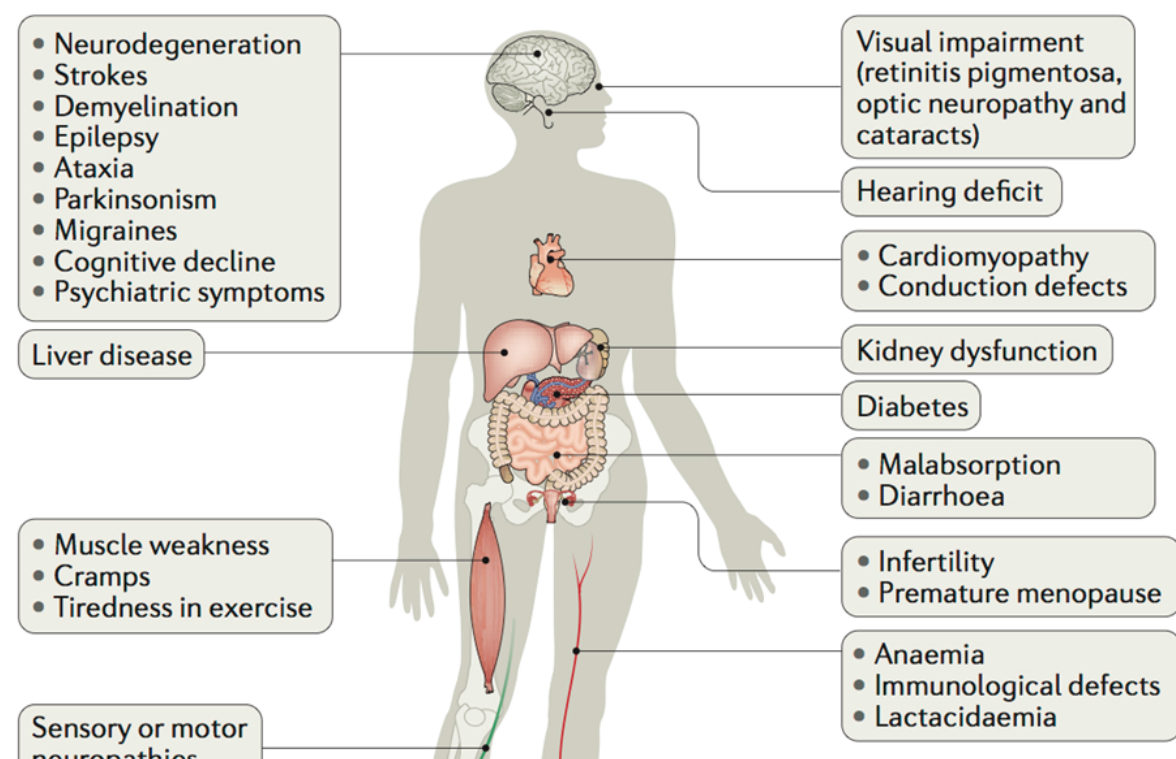

Figure 7. The variability of mitochondrial disease manifestations.(18) (Adapted with permission from Springer Nature).

we can now send the patients for a better explanation about their disease, and some options for new treatments, then there is a clear pathway towards a more comprehensive treatment in the near future.(164) Mitochondrial dysfunction is now there to be "blamed" for many medical conditions including diabetes, inflammation, cancer and neurodegeneration thus we need to expand our knowledge either on primary or secondary pathomechanism of mitochondrial impairment and to prompt the development of more effective, evidencebased therapeutic approaches.(14) Some studies tried to utilize the tandem actions of that nuclear and mitochondrial miRNA to alter the tumor microenvironment at the cellular level.(172)

\section{Conclusion}

Mitochondrial function and behavior become central for human physiology, and therefore "mitochondrial dysfunction" take charge to a wide range of diseases. Fortunately, our body has own system for mitochondrial "quality control", monitoring the function of mitochondria in various level, and release mitochondrial signals in particular stress condition, thus lead to a dramatic effect on oxidative and biosynthetic pathways in the cell, affect whole-body metabolism. Mitochondrial dysfunction appears to work on a close link with nutrient-sensing pathways and the onecarbon cycle although still poorly understood. Many efforts to improve our understanding of the metabolic remodeling associated to mitochondrial diseases based on biochemical, metabolic and genomic approaches, expected to enable a construction of a complete human mitochondrial network map. The utilization of NGS technology may exploit the whole mitochondrial DNA and the exons encoding the proteome, and will continue to greatly accelerate these advances..

\section{References}

1. Brentjens RJ9. Duchen MR, Szabadkai G. Roles of mitochondria in human disease. Essays Biochem. 2010; 47: 115-37.

2. Eisner V, Hajnoczky G. mitochondrial fusion dynamics in skeletal muscle. Abstracts of papers at the sixty-fifth annual meeting of the society of general physiologists: mitochondrial physiology and medicine. J Gen Physiol. 2011; 138: 131.

3. Detmer SA, Chan DC. Functions and dysfunctions of mitochondrial dynamics. Nat Rev Mol Cell Biol. 2007; 8: 870-9.

4. Soubannier V, McBride HM. Positioning mitochondrial plasticity within cellular signaling cascades. Biochim Biophys Acta. 2009; 1793: 154-70.

5. Chen H, Chomyn A, Chan DC. Disruption of fusion results in mitochondrial heterogeneity and dysfunction. J Biol Chem. 2005; 280: 26185-92

6. Chen H, Detmer SA, Ewald AJ, Griffin EE, Fraser SE, Chan DC. Mitofusins Mfn1 and Mfn2 coordinately regulate mitochondrial fusion and are essential for embryonic development. J Cell Biol. 2003; 160: 189-200.

7. Yu-Wai-Man P, Chinnery PF. Dysfunctional mitochondrial maintenance: what breaks the circle of life? Brain. 2012; 135: 9-11. 
8. Chen H, Chan DC. Physiological functions of mitochondrial fusion Ann NY Acad Sci. 2010; 1201: 21-5.

9. Frazier AE, Kiu C, Stojanovski D, Hoogenraad NJ, Ryan MT. Mitochondrial morphology and distribution in mammalian cells. Biol Chem. 2006; 387: 1551-8.

10. Liesa $M$, Palacin $M$, Zorzano A. Mitochondrial dynamics in mammalian health and disease. Physiol Rev. 2009; 89: 799-845.

11. Westermann B. Mitochondrial fusion and fission in cell life and death. Nat Rev Mol Cell Biol. 2010; 11: 872-84.

12. Picard M, Shirihai OS, Gentil BJ, van Burelle. Mitochondrial morphology transitions and functions: implications for retrograde signaling? Am J Physiol Regul Integr Comp Physiol. 2013; 304: R393-406.

13. Viscomy C, Bottani E, Zeviani M. Emerging concepts in the therapy of mitochondrial disease. Biochim Biophys Acta. 2015; 1847: 54457.

14. Chinnery PF. Mitochondrial Disorders Overview. In: Adam MP, Ardinger HH, Pagon RA, editors. Gene Reviews. Seattle: University of Washington; 2014. p.1993-2018.

15. Ylikallio E, Suomalainen A. Mechanisms of mitochondrial diseases. Ann Med. 2012; 44: 41-59.

16. Boczonadi V, Horvath R. Mitochondria: impaired mitochondrial translation in human disease. Int J Biochem Cell Biol. 2014; 48: 77-84.

17. Nunnari J, Suomalainen A. Mitochondria: in sickness and in health. Cell. 2012; 148: 1145-59.

18. Suomalainen A, Battersby BJ. Mitochondrial diseases: the contribution of organelle stress responses to pathology. Nat Rev Mol Cell Biol. 2018; 19: 77-92.

19. Balaban RS. Regulation of oxidative phosphorylation in the mammalian cell. Am J Physiol Cell Physiol. 1990; 258: C377-89.

20. Cannon B, Nedergaard J. Brown adipose tissue: function and physiological significance. Physiol Rev. 2004; 84: 277-359.

21. Scarpulla RC, Vega RB, Kelly DP. Transcriptional integration of mitochondrial biogenesis. Trends Endocrinol Metab. 2012; 23: 45966.

22. Villena JA. New insights into PGC-1 coactivators: redefining their role in the regulation of mitochondrial function and beyond. FEBS J. 2014; 282: 647-72.

23. McKenzie M, Lazarou M, Ryan MT. Chapter 18 Analysis of respiratory chain complex assembly with radiolabeled nuclear- and mitochondrial-encoded subunits. Methods Enzymol. 2009; 456: 321-39.

24. Matsuda N, Sato S, Shiba K, Okatsu K, Saisho K, Gautier CA, et al. PINK1 stabilized by mitochondrial depolarization recruits Parkin to damaged mitochondria and activates latent Parkin for mitophagy. J Cell Biol. 2010; 189: 211-21.

25. Ploumi C, Daskalaki I, Tavernarakis N. Mitochondrial biogenesis and clearance: a balancing act. FEBS J. 2016; 284: 183-95.

26. Fraga $\mathrm{H}$, Ventura $\mathrm{S}$. Influence of cytoplasmatic folding on mitochondrial import. Curr Med Chem. 2015; 22: 2349-59.

27. Schulz C, Rehling P. Remodelling of the active presequence translocase drives motor-dependent mitochondrial protein translocation. Nat Commun. 2014; 5: 4349. doi: 10.1038/ncomms5349.

28. Zong H, Ren JM, Young LH, Pypaert M, Mu J, Birnbaum MJ, et al. AMP kinase is required for mitochondrial biogenesis in skeletal muscle in response to chronic energy deprivation. Proc Natl Acad Sci USA. 2002; 99: 15983-7.

29. Cunningham JT, Rodgers JT, Arlow DH, Vazquez F, Mootha VK, Puigserver P. mTOR controls mitochondrial oxidative function through a YY1- PGC-1alpha transcriptional complex. Nature. 2007; 450: 736-40.
30. Lagouge M, Argmann C, Gerhart-Hines Z, Meziane H, Lerin C, Daussin F, et al. Resveratrol improves mitochondrial function and protects against metabolic disease by activating SIRT1 and PGC1alpha. Cell. 2006; 127: 1109-22.

31. Wu H, Kanatous SB, Thurmond FA, Gallardo T, Isotani E, BasselDuby R, et al. Regulation of mitochondrial biogenesis in skeletal muscle by CaMK. Science. 2002; 296: 349-52.

32. Nisoli E, Clementi E, Paolucci C, Cozzi V, Tonello C, Sciorati C, et al. Mitochondrial biogenesis in mammals: the role of endogenous nitric oxide. Science. 2003; 299: 896-9.

33. Domcke S, Bardet AF, Adrian Ginno P, Hartl D, Burger L, Schubeler D. Competition between DNA methylation and transcription factors determines binding of NRF1. Nature. 2015; 528: 575-9.

34. Bruni F, Polosa PL, Gadaleta MN, Cantatore P, Roberti M. Nuclear respiratory factor 2 induces the expression of many but not all human proteins acting in mitochondrial DNA transcription and replication. J Biol Chem. 2010; 285: 3939-48.

35. Ryu D, Jo YS, Lo Sasso G, Stein S, Zhang H, Perino A, et al. A SIRT7dependent acetylation switch of GABPbetal controls mitochondrial function. Cell Metab. 2014; 20: 856-69.

36. Rodgers JT, Lerin C, Haas W, Gygi SP, Spiegelman BM, Puigserver P. Nutrient control of glucose homeostasis through a complex of PGC-1alpha and SIRT1. Nature. 2005; 434: 113-8.

37. Reczek CR, Chandel NS. ROS-dependent signal transduction. Curr Opin Cell Biol. 2015; 33: 8-13

38. Cross CE, Halliwell B, Borish ET, Pryor WA, Ames BN, Saul RL, et al. Oxygen radicals and human disease. Ann Intern Med. 1987; 107: 526-45.

39. Schieber M, Chandel NS. ROS function in redox signaling and oxidative stress. Curr Biol. 2014; 24: R453-62.

40. Sena LA, Chandel NS. Physiological roles of mitochondrial reactive oxygen species. Mol Cell. 2012; 48: 158-67.

41. Holmstrom KM, Finkel T. Cellular mechanisms and physiological consequences of redox-dependent signalling. Nat Rev Mol Cell Biol. 2014; 15: 411-21.

42. Quinlan CL, Treberg JR, Perevoshchikova IV, Orr AL, Brand MD. Native rates of superoxide production from multiple sites in isolated mitochondria measured using endogenous reporters. Free Radic Biol Med. 2012; 53: 1807-17.

43. Brandes RP, Weissmann N, Schroder K. Nox family NADPH oxidases: Molecular mechanisms of activation. Free Radic Biol Med. 2014; 76: 208-26.

44. Murphy M. How mitochondria produce reactive oxygen species. Biochem J. 2009; 417: 1-13. doi: 10.1042/bj20081386.

45. Muller F, Liu Y, Van Remmen H. Complex III releases superoxide to both sides of the inner mitochondrial membrane. J Biol Chem. 2004; 279: 49064-73

46. Lodhi IJ, Semenkovich CF. Peroxisomes: a nexus for lipid metabolism and cellular signaling. Cell Metab. 2014; 19: 380-392.

47. Clapham DE. Calcium signaling. Cell. 2007; 131: 1047-58.

48. Berridge MJ, Bootman MD, Roderick HL. Calcium signalling: dynamics, homeostasis and remodelling. Nature Rev Mol Cell Biol. 2003; 4: 517-29.

49. Rizzuto R, de Stefani D, Raffaello A, Mammucari C. Mitochondria as a sensors and regulators of calcium signaling. Nat Rev Mol Cell Biol. 2012; 13: 566-78.

50. McCormack JG, Halestrap AP, Denton RM. Role of calcium ions in regulation of mammalian intramitochondrial metabolism. Physiol Rev. 1990; 70: 391-425.

51. Hansford RG. Physiological role of mitochondrial Ca2+ transport. J Bioenerg Biomembr. 1994; 26: 495-508.

52. McCormack JG, Denton RM. The effects of calcium ions and 
adenine nucleotides on the activity of pig heart 2-oxoglutarate dehydrogenase complex. Biochem J. 1979; 180: 533-44.

53. Jouaville LS, Pinton P, Bastianutto C, Rutter GA, Rizzuto, R. Regulation of mitochondrial ATP synthesis by calcium: evidence for a long-term metabolic priming. Proc Natl Acad Sci USA. 1999; 96: 13807-12.

54. Brini M, Pinton P, King MP, Davidson M, Schon EA, Rizzuto R. A calcium signaling defect in the pathogenesis of a mitochondrial DNA inherited oxidative phosphorylation deficiency. Nature Med. 1999; 5: 951-4.

55. Visch HJ, Rutter GA, Koopman WJH, Koenderink JB, Verkaart $\mathrm{S}$, de Groot $\mathrm{T}$, et al. Inhibition of mitochondrial $\mathrm{Na}+-\mathrm{Ca} 2+$ exchange restores agonist-induced ATP production and $\mathrm{Ca} 2+$ handling in human complex I deficiency. J Biol Chem. 2004; 279: 40328-36.

56. Bernardi P, Paradisi V, Pozzan T, Azzone GF. Pathway for uncouplerinduced calcium efflux in rat liver mitochondria: inhibition by ruthenium red. Biochemistry. 1984; 23: 1645-51.

57. Mela L. Inhibition and activation of calcium transport in mitochondria. Effect of lanthanides and local anesthetic drugs. Biochemistry. 1969; 8: 2481-6.

58. Bragadin M, Pozzan T, Azzone GF. Activation energies and enthalpies during $\mathrm{Ca} 2+$ transport in rat liver mitochondria. FEBS Lett. 1979; 104: 347-51.

59. Crompton M, Kunzi M, Carafoli E. The calcium-induced and sodiuminduced effluxes of calcium from heart mitochondria. Evidence for a sodium-calcium carrier. Eur J Biochem. 1977; 79: 549-58.

60. Pozzan T, Bragadin M, Azzone GF. Disequilibrium between steady-state $\mathrm{Ca} 2+$ accumulation ratio and membrane potential in mitochondria. Pathway and role of $\mathrm{Ca} 2+$ efflux. Biochemistry. 1977; 16: 5618-25.

61. Cox DA, Conforti L, Sperelakis N, Matlib MA. Selectivity of inhibition of $\mathrm{Na}+-\mathrm{Ca} 2+$ exchange of heart mitochondria by benzothiazepine CGP-37157. J Cardiovasc Pharmacol. 1993; 21: 595-9.

62. Bertero E, Maack C. Calcium signaling and reactive oxygen species in mitochondria. Circ Res. 2018; 122: 1460-78.

63. Dolezal P, Likic V, Tachezy J, Lithgow, T. Evolution of the molecular machines for protein import into mitochondria. Science. 2006; 313: 314-8.

64. Neupert W, Herrmann JM. Translocation of proteins into mitochondria. Annu Rev Biochem. 2007; 76: 723-49.

65. Chacinska A, Koehler CM, Milenkovic D, Lithgow T, Pfanner N. Importing mitochondrial proteins: machineries and mechanisms. Cell. 2009; 138: 628-44.

66. Lill R. Function and biogenesis of iron-sulphur proteins. Nature. 2009; 460: 831-8.

67. Schmidt O, Pfanner N, Meisinger C. Mitochondrial protein import: from proteomics to functional mechanisms. Nat Rev Mol Cell Biol. 2010; 11: 655-67.

68. Hamza I, Dailey HA. One ring to rule them all: trafficking of heme and heme synthesis intermediates in the metazoans. Biochim Biophys Acta. 2012; 1823: 1617-32.

69. Harbauer AB, Zahedi RP, Sickmann A, Pfanner N, Meisinger C. The protein import machinery of mitochondria - a regulatory hub in metabolism, stress, and disease. Cell Metab. 2014; 19: 357-72.

70. Quiros PM, Laber T, Lopez-Otin C. New roles for mitochondrial proteases in health, ageing and disease. Nat Rev Mol Cell Biol. 2015; 16: 345-9.

71. Jiang Y, Wang X. Comparative mitochondrial proteomics: perspective in human disease. J Hematol Oncol. 2012; 5: 11. doi: 10.1186/17568722-5-11.
72. Chen X, Li J, Hou J, Xie Z, Yang F. Mammalian mitochondrial proteomics: insights into mitochondrial functions and mitochondriarelated diseases. Expert Rev Proteomics. 2010; 7: 333-45.

73. Wang C, Youle RJ. The role of mitochondria in apoptosis. Annu Rev Genet. 2009; 43: 95-118.

74. Martinou JC, Youle RJ. Mitochondria in apoptosis: Bcl-2 family members and mitochondrial dynamics. Dev Cell. 2011; 21: 92-101.

75. Baker MJ, Tatsuta T, Langer T. Quality control of mitochondrial proteostasis. Cold Spring Harb Perspect Biol. 2011; 3: a007559. doi: 10.1101/cshperspect.a007559.

76. Baker BM, Haynes CM. Mitochondrial protein quality control during biogenesis and aging. Trends Biochem Sci. 2011; 36: 254-61.

77. Weber TA, Reichert AS. Impaired quality control of mitochondria: aging from a new perspective. Exp Gerontol. 2010; 45: 503-11.

78. Luce K, Weil AC, Osiewacz HD. Mitochondrial protein quality control systems in aging and disease. Adv Exp Med Biol. 2010; 694: 108-25.

79. Tatsuta T, Langer T. Quality control of mitochondria: protection against neurodegeneration and ageing. EMBO J. 2008; 27: 306-14.

80. Rugarli EJ, T. Langer. Mitochondrial quality control: a matter of life and death for neurons. EMBO J. 2012; 31: 1336-49.

81. Anand R, Langer T, Baker MJ. Proteolytic control of mitochondrial function and morphogenesis. Biochim Biophys Acta. 2013; 1833: 195-204.

82. Haynes CM, Ron D. The mitochondrial UPR-protecting organelle protein homeostasis. J Cell Sci. 2010; 123: 3849-55.

83. Livnat-Levanon N, Glickman MH. 2010. Ubiquitin-proteasome system and mitochondria-reciprocity. Biochim Biophys Acta. 2010; 1809: 80-7.

84. Hoppins S, Lackner L, Nunnari J. The machines that divide and fuse mitochondria. Annu Rev Biochem. 2007; 76: 751-80.

85. Otera $\mathrm{H}$, Mihara K. Molecular mechanisms and physiologic functions of mitochondrial dynamics. J Biochem. 2011; 149: 241-51.

86. Wasilewski M, Scorrano L. The changing shape of mitochondrial apoptosis. Trends Endocrinol Metab. 2009; 20: 287-94.

87. Martin SJ. Opening the cellular poison cabinet. Science. 2010; 330: 1330-1.

88. Chen H, Chan DC. Mitochondrial dynamics-fusion, fission, movement, and mitophagy_-in neurodegenerative diseases. Hum Mol Genet. 2009; 18: R169-76.

89. Youle RJ, Narendra DP. Mechanisms of mitophagy. Nat Rev Mol Cell Biol. 2011; 12: 9-14.

90. Lightowiers RN, Taylor RW, Turnbull DM. Mutations causing mitochondrial disease: What is new and what challenges remain? Science. 2015; 349: 1494-9.

91. Rehling P, Model K, Brandner K, Kovermann P, Kovermann A, Meyer HE, et al. Protein insertion into the mitochondrial inner membrane by a twin-pore translocase. Science. 2003; 299: 1747-51.

92. Ahting U, Thun C, Hegerl R, Typke D, Nargang FE, Neupert W, et al. The TOM core complex: the general protein import pore of the outer membrane of mitochondria. J. Cell Biol. 1999; 147: 959-68.

93. Model K, Meisinger C, Kühlbrandt W. Cryo-electron microscopy structure of a yeast mitochondrial preprotein translocase. J Mol Biol. 2008; 383: 1049-57.

94. Saitoh T, Igura M, Obita T, Ose T, Kojima R, Maenaka K, et al. Tom20 recognizes mitochondrial presequences through dynamic equilibrium among multiple bound states. EMBO J. 2007; 26: 477787.

95. Webb CT, Gorman MA, Lazarou M, Ryan MT, Gulbis JM. Crystal structure of the mitochondrial chaperone TIM9-10 reveals a sixbladed $\alpha$-propeller. Mol Cell. 2006; 21: 123-33. 
96. Li J, Qian X, Hu J, Sha B. Molecular chaperone Hsp70/Hsp90 prepares the mitochondrial outer membrane translocon receptor Tom71 for preprotein loading. J Biol Chem. 2009; 284: 23852-9.

97. Albrecht R, Rehling P, Chacinska A, Brix J, Cadamuro SA, Volkmer $\mathrm{R}$, et al. The Tim 21 binding domain connects the preprotein translocases of both mitochondrial membranes. EMBO Rep. 2006; 7: 1233-8.

98. Mokranjac D, Bourenkov G, Hell K, Neupert W, Groll M. Structure and function of Tim14 and Tim16, the J and J-like components of the mitochondrial protein import motor. EMBO J. 2006; 25: 467585.

99. Taylor AB, Smith BS, Kitada S, Kojima K, Miyaura H, Otwinowski $Z$, et al. Crystal structures of mitochondrial processing peptidase reveal the mode for specific cleavage of import signal sequences. Structure. 2001; 9: 615-25.

100. Baker MJ, Frazier AE, Gulbis JM, Ryan MT. Mitochondrial proteinimport machinery: correlating structure with function. Trends Cell Biol. 2007; 17: 456-64.

101. Kang C, Li Ji L. Role of PGC-1alpha signaling in skeletal muscle health and disease, Ann NY Acad Sci. 2012; 1271: 110-17.

102. Piantadosi CA, Suliman HB. Redox regulation of mitochondrial biogenesis. Free Radic Biol Med. 2012; 53: 2043-53.

103. Wenz T. Regulation of mitochondrial biogenesis and PGC-1alpha under cellular stress. Mitochondrion. 2013; 13: 134-42.

104. Scarpulla RC. Nuclear control of respiratory gene expression in mammalian cells, J Cell Biochem. 2006; 97: 673-683.

105. Scarpulla RC. Metabolic control of mitochondrial biogenesis through the PGC-1 family regulatory network. Biochim Biophys Acta. 2011; 1813: 1269-78.

106. Schreiber SN, Emter R, Hock MB, Knutti D, Cardenas J, Podvinec $\mathrm{M}$, et al. The estrogen-related receptor alpha (ERRalpha) functions in PPARgamma coactivator 1alpha (PGC-1alpha)-induced mitochondrial biogenesis. Proc Natl Acad Sci USA. 2004; 101: 6472-7.

107. Basu A, Lenka N, Mullick J, Avadhani NG. Avadhani, Regulation of murine cytochrome oxidase $\mathrm{Vb}$ gene expression in different tissues and during myogenesis. Role of a YY-1 factor-binding negative enhancer. J Biol Chem. 1997; 272: 5899-908.

108. Vercauteren K, Pasko RA, Gleyzer N, Marino VM, Scarpulla RC. PGC-1-related coactivator: immediate early expression and characterization of a CREB/NRF-1 binding domain associated with cytochrome c promoter occupancy and respiratory growth. Mol Cell Biol. 2006; 26: 7409-19.

109. Kotiadis VN, Duchen MR, Osellame LD. Mitochondrial quality control and communications with the nucleus are important in maintaining mitochondrial function and cell health. Biochim Biophys Acta. 2014; 1840: 1254-65.

110. Jazwinski SM. The retrograde response: when mitochondrial quality control is not enough. Biochim Biophys Acta. 2013; 1833: 400-9.

111. Laplante M, Sabatini DM. mTOR signaling in growth control and disease. Cell. 2012; 149: 274-93.

112. Wallace DC. Bioenergetic origins of complexity and disease. Cold Spring Harb Symp Quant Biol. 2011; 76: 1-16. doi: 10.1101/ sqb.2011.76.010462.

113. Wallace DC. Mitochondrial DNA mutations in disease and aging. Environ Mol Mutagen. 2010; 51: 440-50.

114. Schapira AH. Mitochondrial diseases. Lancet. 2012; 379: 1825-34.

115. Holt IJ, Harding AE, Morgan-Hughes JA. Deletions of muscle mitochondrial DNA in patients with mitochondrial myopathies. Nature. 1988; 331: 717-9.

116. Kabekkodu SP, Chakrabarty S, Shukla V, Varghese VK, Singh KK, Thangaraj K, et al. Mitochondrial biology: From molecules to diseases. Mitochondrion. 2015; 24: 93-8.
117. Nakatogawa H, Suzuki K, Kamada Y, Ohsumi Y. Dynamics and diversity in autophagy mechanisms: lessons from yeast. Nature Rev Mol Cell Biol. 2009; 10: 458-67.

118. Yang Z, Klionsky DJ. Eaten alive: a history of macroautophagy. Nature Cell Biol. 2010; 12: 814-22.

119. Tondera D, Grandemange S, Jourdain A, Karbowski M, Mattenberger Y, Herzig S, et al. SLP-2 is required for stress-induced mitochondrial hyperfusion. EMBO J. 2009; 28: 1589-600.

120. Youle RJ, van der Bliek AM. Mitochondrial fission, fusion, and stress. Science. 2012; 337: 1062-5.

121. Scarffe LA, Stevens DA, Dawson VL, Dawspn TM. Parkin and PINK1: much more than mitophagy. Trends Neurosci. 2014; 37 : 315-24.

122. Novak I, Kirkin V, McEwan DG, Zhang J, Wild P, Rozenknop A, et al. Nix is a selective autophagy receptor for mitochondrial clearance. EMBO Rep. 2010; 11: 45-51.

123. Valente EM, Abou-Sleiman PM, Caputo V, Muqit MMK, Harvey K, Gispert S, et al. Hereditary early-onset Parkinson's disease caused by mutations in PINK1. Science. 2004; 304: 1158-60.

124. Kitada T, Asakawa S, Hattori N, Matsumine H, Yamamura Y, Minoshima S, et al. Mutations in the parkin gene cause autosomal recessive juvenile parkinsonism. Nature. 1998; 392: 605-8.

125. Greene JC, Whitworth AJ, Kuo I, Andrews LA, Feany MB, Pallanck LJ. Mitochondrial pathology and apoptotic muscle degeneration in Drosophila parkin mutants. Proc Natl Acad Sci USA. 2003; 100: 4078-83.

126. Park J, Lee SB, Lee S, Kim Y, Song S, Kim S, et al. Mitochondrial dysfunction in Drosophila PINK1 mutants is complemented by parkin. Nature. 2006; 441: 1157-61.

127. Clark IE, Dodson MW, Jiang C, Cao JH, Huh JR, Seol JH, et al. Drosophila pink1 is required for mitochondrial function and interacts genetically with parkin. Nature. 2006; 441: 1162-6.

128. Poole AC, Thomas RE, Andrews LA, McBride HM, Whitworth AJ, Pallanck LJ. The PINK1/Parkin pathway regulates mitochondrial morphology. Proc Natl Acad Sci USA. 2008; 105: 1638-43.

129. Yang Y, Ouyang Y, Yang L, Beal MF, McQuibban A, Vogel H, et al. Pink1 regulates mitochondrial dynamics through interaction with the fission/fusion machinery. Proc Natl Acad Sci USA. 2008; 105: 7070-5.

130. Deng H, Dodson MW, Huang H, Guo M. The Parkinson's disease genes pink1 and parkin promote mitochondrial fission and/or inhibit fusion in Drosophila. Proc Natl Acad Sci USA. 2008; 105: 14503-8.

131. Marino G, Niso-Santano M, Baehrecke EH, Kroemer G. Selfconsumption: the interplay of autophagy and apoptosis. Nat Rev Mol Cell Biol. 2014; 15: 81-94.

132. Liu Z, Butow RA. Mitochondrial retrograde signaling. Annu Rev Genet. 2006; 40: 159-85.

133. Hardie DG, Schaffer BE, Brunet A. AMPK: an energy-sensing pathway with multiple inputs and outputs. Trends Cell Biol. 2015; 26: 190-201.

134. Harbauer AB, Zahedi RP, Sickmann A, Pfanner N, Meisinger, C. The protein import machinery of mitochondria-a regulatory hub in metabolism, stress, and disease. Cell Metab. 2014; 19: 357-72.

135. Shariff K, Ghosal S, Matouschek A. The force exerted by the membrane potential during protein import into the mitochondrial matrix. Biophys. J. 2004; 86: 3647-52.

136. van der Laan M, Wiedemann N, Mick DU, Guiard B, Rehling P, Pfanner N. A role for Tim21 in membrane-potential-dependent preprotein sorting in mitochondria. Curr Biol. 2006; 16: 2271-6.

137. Kikis EA, Gidalevitz T, Morimoto RI. Protein homeostasis in models of aging and age-related conformational disease. Adv Exp Med Biol. 2010; 694: 138-59. 
138. Vabulas RM, Raychaudhuri S, Hayer-Hartl M, Hartl FU. Protein folding in the cytoplasm and the heat shock response. Cold Spring Harb Perspect Biol. 2010; 2: a004390. doi: 10.1101/cshperspect. a004390.

139. Walter P, Ron D. The unfolded protein response: from stress pathway to homeostatic regulation. Science. 2011; 334: 1081-6.

140. Jovaisaite V, Mouchiroud L, Auwerx J. The mitochondrial unfolded protein response, a conserved stress response pathway with implications in health and disease. J Exp Biol. 2014; 217: 136-43.

141. Jovaisaite V, Auwerx J. The mitochondrial unfolded protein response — synchronizing genomes. Curr Opin Cell Biol. 2015; 33: 74-81.

142. Taylor RC, Dillin A. Aging as an event of proteostasis collapse. Cold Spring Harb Perspect Biol. 2011; 3: pii: a004440. doi: 10.1101/ cshperspect.a004440.

143. Schulz AM, Haynes CM. UPRmt-mediated cytoprotection and organismal aging. Biochim Biophys Acta. 2015; 1847: 1448-56.

144. Houtkooper RH, Mouchiroud L, Ryu D, Moullan N, Katsyuba E, Knott G, et al. Mitonuclear protein imbalance as a conserved longevity mechanism. Nature. 2013; 497: 451-7.

145. Wu Y, Williams Evan G, Dubuis S, Mottis A, Jovaisaite V, Houten, et al. Multilayered genetic and omics dissection of mitochondrial activity in a mouse reference population. Cell. 2014; 158: 1415-30.

146. Durieux J, Wolff S, Dillin A. The cell-non-autonomous nature of electron transport chain-mediated longevity. Cell. 2011; 144: 79-91.

147. Rath E, Berger E, Messlik A, Nunes T, Liu B, Kim SC, et al. Induction of dsRNA- activated protein kinase links mitochondrial unfolded protein response to the pathogenesis of intestinal inflammation. Gut. 2012, 61: 1269-78.

148. Runkel ED, Liu S, Baumeister R, Schulze E. Surveillance-activated defenses block the ROS-induced mitochondrial unfolded protein response. PLoS Genet. 2013; 9: e1003346. doi: 10.1371/journal. pgen.1003346.

149. Liu Y, Samuel BS, Breen PC, Ruvkun G. Caenorhabditis elegans pathways that surveil and defend mitochondria. Nature. 2014, 508: 406-10.

150. Mouchiroud L, Houtkooper RH, Moullan N, Katsyuba E, Ryu D, Canto $\mathrm{C}$, et al. The $\mathrm{NAD}(+) /$ sirtuin pathway modulates longevity through activation of mitochondrial UPR and FOXO signaling. Cell. 2013, 154: 430-41.

151. Pirinen E, Canto C, Jo YS, Morato L, Zhang H, Menzies KJ, et al. Pharmacological inhibition of poly(ADP-ribose) polymerases improves fitness and mitochondrial function in skeletal muscle. Cell Metab. 2014; 19: 1034-41.

152. Baker BM, Nargund AM, Sun T, Haynes CM. Protective coupling of mitochondrial function and protein synthesis via the eIF2alpha kinase GCN-2. PLoS Genet. 2012; 8: e1002760. doi: 10.1371/ journal.pgen.1002760.

153. Rainbolt TK, Atanassova N, Genereux JC, Wiseman RL. Stressregulated translational attenuation adapts mitochondrial protein import through Tim17A degradation. Cell Metab. 2013, 18: 908-19.

154. Nargund AM, Pellegrino MW, Fiorese CJ, Baker BM, Haynes CM. Mitochondrial import efficiency of ATFS-1 regulates. Science. 2012; 337: 587-90.
155. Yun J, Finkel T. Mitohormesis. Cell Metab 2014; 19: 757-66.

156. Calabrese EJ, Baldwin LA. Defining hormesis. Hum Exp Toxicol. 2002; 21: 91-7.

157. Suomalainen A. Therapy for mitochondrial disorders: little proof, high research activity, some promise. Semin Fetal Neonatal Med. 2011; 16: 236-40.

158. Grady JP, Campbell G, Ratnaike T, Blakely EL, Falkous G, Nesbitt $\mathrm{V}$, et al. Disease progression in patients with single, large-scale mitochondrial DNA deletions. Brain. 2014; 137: 323-34.

159. Koopman WJ, Willems PH, Smeitink JA. Monogenic mitochondrial disorders. N Engl J Med. 2012; 366: 1132-41.

160. Ghezzi D, Zeviani M. Assembly factors of human mitochondrial respiratory chain complexes: physiology and pathophysiology. Adv Exp Med Biol. 2012; 748: 65-106.

161. Fernandez-Vizarra E, Zeviani M. Nuclear gene mutations as the cause of mitochondrial complex III deficiency. Front Genet. 2015; 6: 134. doi: 10.3389/fgene.2015.00134.

162. Fujikawa M, Sugawara K, Tanabe T, Yoshida M. Assembly of human mitochondrial ATP synthase through two separate intermediates, F-c-ring and b-e-g complex. FEBS Lett. 2015; 589: 2707-12.

163. Elguindy MM, Nakamaru-Ogiso E. Apoptosis-inducing factor (AIF) and its family member protein, AMID, are rotenone-sensitive NADH: ubiquinone oxidoreductases (NDH-2). J Biol Chem. 2015; 290: 20815-26

164. Chinnery PF. Mitochondrial disease in adults: what's old and what's new? EMBO Mol Med. 2015; 7: 1503-12.

165. Nikkanen J, Forsström S, Euro L, Paetau I, Kohnz RA, Wang L, et al. Mitochondrial DNA replication defects disturb cellular dNTP pools and remodel one-carbon metabolism. Cell Metab. 2016; 23 : $635-48$.

166. Richter U, Lahtinen T, Marttinen P, Myöhänen M, Greco D, Cannino $\mathrm{G}$, et al. A mitochondrial ribosomal and RNA decay pathway blocks cell proliferation. Curr Biol. 2013; 23: 535-41.

167. Bao XR, Ong SE, Goldberger O, Peng J, Sharma R, Thompson DA, et al. Mitochondrial dysfunction remodels one-carbon metabolism in human cells. eLife. 2016; 5: e10575. doi: 10.7554/eLife.10575.

168. Tyynismaa H1, Carroll CJ, Raimundo N, Ahola-Erkkilä S, Wenz T, Ruhanen $\mathrm{H}$, et al. Mitochondrial myopathy induces a starvation-like response. Hum Mol Genet. 2010; 19: 3948-58.

169. Dogan SA, Pujol C, Maiti P, Kukat A, Wang S, Hermans S, et al. Tissue-specific loss of DARS2 activates stress responses independently of respiratory chain deficiency in the heart. Cell Metab. 2014; 19: 458-69.

170. Yoshida H, Haze K, Yanagi H, Yura T, Mori K. identification of thecisacting endoplasmic reticulum stress response element responsible for transcriptional induction of mammalian glucose-regulated proteins J Biol Chem. 1998; 273: 33741-9.

171. Zhao Q, Wang J, Levichkin IV, Stasinopoulos S, Ryan MT, Hoogenraad NJ. A mitochondrial specific stress response in mammalian cells. EMBO J. 2002; 21: 4411-9.

172. Chakrabarty S, Kabekkodu SP, Singh RP, Thangaraj K, Singh KK, Satyamoorthy K. Mitochondria in health and disease. Mitochondrion. 2018; 43: 25-9. 